\title{
PRODUÇÃO DE GELÉIA DE JAMBOLÃo (Syzygium cumini Lamarck): PROCESSAMENTO, PARÂMETROS FÍSICO - gUÍMICOS E AVALIAÇÃO SENSORIAL ${ }^{1}$
}

\author{
Ellen Silva LAGO², Eleni GOMES ${ }^{3}$, Roberto da SILVA,**
}

\begin{abstract}
RESUMO
A fruta jambolão (Syzygium cumini Lamarck) é uma fruta de coloração roxa intensa e sabor agradável. Dado que não há na literatura nenhum relato de seu aproveitamento industrial, a produção de geléia de jambolão tornou-se uma interessante atividade de pesquisa. Este trabalho objetivou a elaboração e a avaliação das características físico-químicas e sensoriais da geléia obtida do jambolão. A fruta apresentou a seguinte composição química: cinzas, 0,34\%; lipídeos, 0,30\%; proteínas, 0,67\%; carboidratos, 10,07\%; fibras, 0,28\%; umidade, 87,75\%; frutose, 0,4\%; glicose, 0,6\%; antocianinas totais, 0,276\%; substâncias pécticas, $0,245 \%$; acidez titulável, $5,91 \%$; sólidos solúveis, 9,00\%; e pH, 3,9. A geléia obtida apresentou a seguinte composição: açúcares redutores, 20,99\%; não-redutores, 18,01\%; açúcares totais, 39,00\%; pH, 3,42; sólidos solúveis, $67^{\circ} \mathrm{Brix}$; acidez titulável, 5,47\%; e umidade, 29,63\%. A análise sensorial foi realizada por uma equipe de 50 provadores não treinados que avaliaram os atributos cor, aparência, odor, textura, sabor e avaliação global, pelo método de escala hedônica com nove pontos. Os resultados obtidos mostraram que o atributo cor foi o que mais agradou aos provadores, o atributo odor foi o menos apreciado. Em conclusão, o estudo de análise sensorial revelou uma aceitação satisfatória da geléia de jambolão.
\end{abstract}

Palavras-chave: jambolão, geléia, antocianina, análise sensorial.

\section{SUMMARY}

PRODUCTION OF JAMBOLAN (Syzygium cumini Lamarck) JELLY: PROCESSING, PHYSICAL-CHEMICAL PROPERTIES AND SENSORY EVALUATION. Jambolan (Syzygium cumini Lamarck) is a purple colored and very tasty fruit. Since there are no reports of its industrial use, the production of this jelly has become a matter of interest for research. The purpose of this work is to develop and evaluate the physical-chemical and sensory characteristics of the jelly made of jambolan. The fruit showed the following chemical composition: ash, $0.34 \%$; lipids, $0.30 \%$; proteins, $0.67 \%$; carbohydrates, $10.07 \%$; fibers, $0.28 \%$; moisture, $87.75 \%$; fructose, $0.4 \%$; glucose, $0.6 \%$; total anthocyanins, $0.276 \%$; pectic substances, $0.245 \%$; acidity (direct titration), $5.91 \%$; soluble solids, $9.00 \%$ and pH 3.9 . The jelly showed the following composition: reducing sugars, $20.99 \%$; non-reducing, $18.01 \%$; total sugars, $39.00 \%$; pH, 3.42 ; soluble solids, $67{ }^{\circ} \mathrm{Brix}$; acidity (direct titration), $5.47 \%$ and moisture, $29.63 \%$. The sensory analysis was made by a non-trained-50-member panel who evaluated the color of the attributes, appearance, aroma, texture, taste and overall evaluation on a 9-point hedonic scale. The results showed that color was the most appreciated attribute while aroma was the least appreciated. In conclusion, the sensory analysis study revealed satisfactory acceptance of jambolan jelly.

Keywords: jambolan, jelly, anthocyanin, sensory analysis.

\section{1 - INTRODUÇÃO}

O Brasil é um dos três maiores produtores mundiais de frutas, algo em torno de 39 milhões de toneladas por ano [15]. Esta elevada produção de diferentes variedades de frutíferas nativas ou adaptadas é decorrência da extensão do território e sua inserção, em grande parte, nas zonas de clima tropical e temperado [16]. A fruticultura nacional, no entanto, tem ainda grande potencial de expansão, pois há inúmeras frutas nativas e exóticas muito pouco exploradas

\footnotetext{
${ }^{1}$ Recebido para publicação em 21/02/2006. Aceito para publicação em 20/10/2006 (001674)

${ }^{2}$ Programa de Pós-graduação em Engenharia e Ciência de Alimentos, Universidade Estadual Paulista (UNESP).

Campus de São José do Rio Preto.

${ }^{3}$ Departamento de Biologia, Universidade Estadual Paulista (UNESP), Campus de São José do Rio Preto.

${ }^{4}$ Departamento de Química e Ciências Ambientais,

Universidade Estadual Paulista (UNESP),

Campus de São José do Rio Preto, Rua Cristóvão Colombo, 2265,

CEP 15054-000, São José do Rio Preto (SP), Brasil,

E-mail:dasilva@ibilce.unesp.br

* A quem a correspondência deve ser enviada
}

economicamente, cujos estudos para transformá-las em culturas racionais, na sua maioria, estão em andamento, como por exemplo, atemóia, maná, canistel, mirtilo, lichia, physalis, carambola, entre outras [21, 31]. O Instituto Brasileiro de Frutas (IBRAF), em São Paulo, reconhece a importância deste nicho do mercado, mas admite que, por enquanto, não está contabilizado na produção nacional [21].

Dentre inúmeras frutas, o jambolão é obtido de uma árvore pertencente à família Myrtacea, botanicamente classificada como Eugenia jambolana, e, posteriormente, reclassificada, como Syzygium cumini [20]. Disseminada em toda a região noroeste do Estado de São Paulo, o jambolão se adaptou ao clima e solo. A fruta é pequena e de forma ovóide, que se torna roxa escura quando completamente madura. Sua pele é fina, lustrosa e aderente. Sua polpa, também roxa, é carnosa e envolve um caroço único e grande. O sabor, apesar de um pouco adstringente, é agradável ao paladar, e a cor apresenta grande impacto visual [25]. Uma parte de sua produção é aproveitada pelas populações locais, entretanto uma grande parte de suas frutas é desperdiçada na época da safra, em virtude da alta produção por árvore, 
da curta vida útil da fruta in natura e, principalmente, por falta de seu aproveitamento processado.

A coloração característica do jambolão se deve ao alto teor de pigmentos antociânicos [5]. Este composto natural tem despertado interesse, devido aos seus efeitos nutricionais e terapêuticos, pela ação antioxidante. A importância de radicais livres na manifestação de diversas patologias, como câncer e aterosclerose tem levado a crescente busca por fontes ainda não exploradas que possam atuar como antioxidantes e, dessa forma, reduzir o desequilíbrio entre o sistema de defesa antioxidativo do organismo humano e os radicais livres [8].

Em alguns países, como a Índia, além de ser consumido in natura, o jambolão também é utilizado como ingrediente de diversos produtos, hábito ainda não incorporado em nosso país [25]. Deste modo, como forma de agregar valor à fruta, pensou-se em utilizá-la como um ingrediente na elaboração de geléias, visto que pode contribuir com as ações de acidificante, corante e flavorizante deste produto [19].

As Normas Técnicas Relativas a Alimentos e Bebidas, constantes da Resolução n $^{\circ} 12$ de 24 de julho de 1978, estabelece que geléia de fruta é o produto obtido pela cocção de frutas, inteiras ou em pedaços, polpa ou suco de fruta, com açúcar e água e concentrado até a consistência gelatinosa, podendo sofrer a adição de glicose ou açúcar invertido. Ela não pode ser colorida nem aromatizada artificialmente, sendo tolerada a adição de acidulantes e de pectina, caso necessário, para compensar qualquer deficiência do conteúdo natural de acidez da fruta e/ou de pectina. A consistência deve ser tal que, quando extraída de seu recipiente, seja capaz de se manter no estado semi-sólido. Uma combinação adequada desses componentes, tanto na qualidade como na ordem de colocação durante o processamento, deve ser respeitada para obter uma maior qualidade da geléia [1, 6].

Desta forma, dada a ausência de informações na literatura especializada, este estudo objetivou utilizar a fruta jambolão para preparar geléias, bem como analisar sensorialmente a aceitação deste produto por um painel de consumidores.

\section{2 - MATERIAL E MÉTODOS}

\section{1 - Materiais}

Devido à sazonalidade, as coletas da fruta foram feitas no período de dezembro/janeiro de 2005 no Distrito de São José do Rio Preto, SP, Brasil e transportadas para o Laboratório de Bioquímica e Microbiologia Aplicada do Campus da Unesp de São José do Rio Preto. Foram desprezadas as frutas que continham rachaduras, picadas de insetos e/ou ataques de animais ou aves. Depois de selecionadas, estas foram acondicionadas em sacos plásticos, em porções de $500 \mathrm{~g}$, que foram armazenados sob congelamento a $-18{ }^{\circ} \mathrm{C}$. Foram utilizados: sacarose (adquirida no comércio local); glicose (marca comercial Plury Química Ltda); pectina de alto (ATM) e de médio (MTM) teor de metoxilação (marca comercial Kelco); e ácido cítrico de grau alimentício.

\section{2 - Métodos}

\subsection{1 - Análise física e química da matéria-prima}

As frutas foram homogeneizadas em mixer e alíquotas foram retiradas para cada uma das análises: lipídeos totais, a partir do método de BLIGH \& DYER [3]; carboidratos totais, pelo método de DULBOIS et al. [12]; umidade, cinzas, teor de sólidos solúveis, teor de proteínas, acidez titulável (em ácido cítrico) e $\mathrm{pH}$, de acordo com os métodos preconizados pelo Instituto Adolfo Lutz [28]; fibra alimentar total, proposta pela AOAC [2]; carboidratos solúveis, segundo MILLER [24]; antocianinas totais, de acordo com metodologia descrita por FULEKI \& FRANCIS [13, 14]; e pectinas totais, de acordo com o método descrito por SHELUKHINA \& FEDICHKINA [30]. O rendimento em polpa foi calculado pela relação percentual entre peso de fruta inteira e peso de polpa [22].

\subsection{2 - Processamento da geléia}

Para a obtenção da polpa de jambolão, as frutas foram cortadas com faca de aço inoxidável e a separação do caroço foi feita manualmente, sendo este descartado. As frutas (isoladas do caroço) foram homogeneizadas com água numa proporção (p/v) de fruta:água de 0,7:0,3 com o auxílio de um mixer. A separação entre a pele e a polpa do jambolão foi possível com o uso de uma peneira de diâmetro $0,59 \mathrm{~mm}$. $\mathrm{O}$ pH da polpa obtida foi ajustado para 3,4 com o uso do acidulante ácido cítrico e a geléia foi elaborada usando-se uma proporção de polpa:açúcar de 0,6:0,4 (sendo que para o açúcar estabeleceu-se uma proporção de sacarose:glicose de $0,8: 0,2$ ) e $1 \%$ de pectina (numa proporção de pectina de alto teor de metoxilação (ATM):médio teor de metoxilação (MTM) de 0,7:0,3).

Procedeu-se à cocção em tacho de aço inoxidável com capacidade para cinco litros, com agitação manual contínua até concentração final de sólidos solúveis de $67^{\circ} \mathrm{Brix}$, medido em refratômetro. Após esta etapa, a geléia foi envasada a quente em embalagens de vidro com capacidade para $250 \mathrm{~g}$, previamente esterilizadas a $121{ }^{\circ} \mathrm{C} / 15 \mathrm{~min}$; fechadas com tampa de metal; imediatamente resfriadas por adição de água fria por $15 \mathrm{~min}$; e estocadas à temperatura ambiente.

\subsection{3 - Determinação das características físico-químicas da geléia}

A geléia foi analisada quanto ao $\mathrm{pH}$, sólidos solúveis ( ${ }^{\circ}$ Brix), açúcares redutores e não redutores, acidez titulável (em ácido cítrico) e umidade de acordo com os métodos preconizados pelo Instituto Adolfo Lutz [28].

\subsection{4 - Teste sensorial de aceitação}

O teste de aceitação foi realizado em cabines individuais com luz branca no Laboratório de Análise Sensorial do Departamento de Engenharia de Alimentos da Universidade 
jambolão o torna interessante num eventual processamento de uma geléia de baixa caloria.

\section{2 - Adequação da tecnologia convencional para processamento de geléia de jambolão}

Inicialmente, foram realizados vários testes com diferentes proporções polpa:água. Padronizou-se à proporção (v/v) de 0,7:0,3, que resultou em geléia com melhor sabor característico da fruta. Após o preparo da geléia, para melhorar sua aparência, percebeu-se a necessidade de separar a pele da polpa. O processamento foi, então, repetido e esta etapa, efetuada com o auxílio de uma peneira de diâmetro de $0,59 \mathrm{~mm}$.

À polpa de jambolão, foram adicionadas sacarose e glicose (numa proporção (p/p) de 0,8:0,2), considerando-se as proporções para uma geléia tipo extra [6]. Entretanto, esta proporção resultou em uma geléia muito adocicada e, após vários testes, padronizou-se a proporção polpa:açúcar (v/p) que apresentou paladar mais agradável $(0,6: 0,4)$. A geléia foi concentrada até $67{ }^{\circ}$ Brix e enquadra-se dentro das indicações das Normas Técnicas Relativas a Alimentos e Bebidas, constantes da Resolução n ${ }^{\circ} 12$ de 24 de julho de 1978 [6].

Como a polpa da fruta possui um pH de 3,9, fez-se necessário abaixar seu $\mathrm{pH}$ para obter uma geleificação adequada e realçar o sabor natural da fruta. O pH ideal varia em função do teor de sólidos solúveis e, deste modo, para uma concentração de $67{ }^{\circ} \mathrm{Brix}$, a literatura recomenda a adição de ácidos até a polpa atingir um pH máximo de 3,4 [19]. Para tanto, foi usado como acidulante o ácido cítrico que, segundo a Resolução CNS/MS n 04 , de 24 de novembro de 1988 sobre aditivos intencionais utilizados em geléias, tem uso livre [7].

Depois de verificada a necessidade da adição de pectina para compensar a deficiência no conteúdo natural da fruta, foram testadas pectina ATM, MTM e uma combinação das duas (numa proporção de 0,7:0,3, respectivamente), com porcentagens de 1,0\% e 1,5\%. Após os testes de bancada, os dados obtidos demonstraram que o uso combinado das pectinas de ATM e MTM a $1 \%$ resultou em melhor textura na geléia de jambolão. Para não comprometer a qualidade do produto e garantir uma vida de prateleira adequada, foi empregada a técnica de enchimento a quente $\left(90-92{ }^{\circ} \mathrm{C}\right)$, a qual foi condizente com a estabelecida para embalagens de 250 g [33]. Devido à concentração de sacarose relativamente alta na composição da geléia, não foi necessária a adição de conservante.

\section{3 - Caracterização físico-química da geléia de jambolão}

Os resultado da caracterização físico-química da geléia estão apresentadas na Tabela 2.

Observa-se que a média dos valores encontrados para umidade e teor de sólidos solúveis situa-se na faixa encon- trada para a maioria das geléias que são de no máximo 35\% p/p e mínimo de $65 \%$ p/p, respectivamente [6]. Sabe-se que a acidez e o pH das geléias devem ser controlados. A acidez total não deve exceder a $0,8 \%$, e o mínimo indicado é de $0,3 \%$. Quanto ao pH, sugere-se um pH máximo de 3,4, sendo que abaixo de 3,0 ocorre uma tendência à sinérese. Pela Tabela 2 , mostra-se que a geléia obtida apresenta o valor máximo de $\mathrm{pH}$ recomendado, no qual não foi observado prejuízo na formação do gel, e apresenta acidez mediana, não afetando assim a elasticidade da geléia devido à hidrólise da pectina. Observou-se, também, que a geléia de jambolão apresentou teores de açúcares totais menores que os encontrados normalmente para geléias de frutas convencionais, como por exemplo, a de pêssego $(67,35 \%)$ e a de amora $(64,62 \%)$, citadas por ROCHA et al. [29] e NACHTIGALL et al. [27], respectivamente. Esta diminuição da quantidade de açúcares (glicose e sacarose) adicionados apresentou efeito positivo sobre a qualidade química e sensorial da geléia, uma vez que evita o sabor extremamente doce.

TABELA 2 - Resultados estatísticos obtidos das análises físicoquímicas da geléia de jambolão.

\begin{tabular}{lccc}
\hline \multicolumn{1}{c}{ Determinações } & Média & Desvio Padrão & CV (\%) \\
\hline Umidade (\%) & 29,66 & $\pm 0,05$ & 0 \\
Sólidos Solúveis Totais ( ${ }^{\circ}$ Brix) & 67,00 & - & - \\
Açúcares Redutores (\% glicose) & 20,99 & $\pm 0,08$ & 0 \\
Açúcares Não-Redutores & 18,01 & $\pm 0,10$ & 0 \\
(\% sacarose) & 39,00 & $\pm 0,05$ & 0 \\
Açúcares Totais & 0,55 & $\pm 0,01$ & 1 \\
Acidez (\%) (em ácido cítrico) & 3,41 & $\pm 0,01$ & 0 \\
pH & &
\end{tabular}

\section{4 - Análise sensorial}

Os resultados da análise sensorial da geléia de jambolão estão apresentados na Tabela 3.

TABELA 3 - Determinações sensoriais da geléia de jambolão.

\begin{tabular}{lccc}
\hline \multicolumn{1}{c}{ Atributos } & Médias Observadas & Desvio Padrão & CV (\%) \\
\hline Cor & 8 & 1 & 13 \\
Aparência & 7 & 1 & 16 \\
Odor & 6 & 1 & 22 \\
Textura & 7 & 1 & 18 \\
Sabor & 7 & 1 & 20 \\
Avaliação Global & 7 & 1 & 14 \\
\hline
\end{tabular}

Nota-se que o atributo cor foi o que mais agradou aos provadores (nota 8). Isto era esperado devido à coloração roxa atraente da fruta e mostrou que o processamento não destruiu a antocianina presente na fruta. Todavia, devido à fruta não ter um odor marcante, o atributo odor foi o menos apreciado pelos provadores (nota 6). Como avaliação global, o estudo de análise sensorial da geléia de jambolão revelou uma aceitação satisfatória, porém deve-se ressaltar que as porcentagens de coeficiente de variação para todos 
os atributos apresentaram-se altas devido ao fato comum de que, em testes de consumidores, estes difiram entre si com relação ao grau de gostar ou desgostar de uma amostra testada.

\section{4 - CONCLUSÃO}

O interesse por fontes alternativas de matéria-prima a custos acessíveis aliado ao crescente interesse por alimentos com atributos funcionais, como é o caso das antocianinas com ação antioxidante, justificam maiores esforços de se estudar o potencial do uso industrial de frutas regionais como o jambolão. Esta fruta apresentou-se como uma matéria-prima de $\mathrm{pH}$ baixo, alta acidez, médio teor de sólidos solúveis e baixo teor de pectina, todavia, sua acidez associada à sua coloração roxa atraente e sabor agradável resultaram em uma geléia com características favoráveis para consumo. O produto mostrou-se apreciado, após análise de aceitação sensorial por 50 provadores que se manifestaram positivamente nos atributos analisados, sendo a cor o atributo mais apreciado e o odor o menos apreciado. A produção de geléia de jambolão mostrou-se viável e certamente representa uma opção a mais ao pequeno produtor e à fruticultura brasileira.

\section{5 - REFERÊNCIAS BIBLIOGRÁFICAS}

[1] ALBUQUERQUE, J. P.; NACCO, R.; FARO, A. Avaliação global de geléias de uva através do método de dados difusos. Ciência e Tecnologia de Alimentos, Campinas, v. 16 , n. 3, p. 250-254, out./dez. 1996

[2] ASSOCIATION OF OFFICIAL ANALYTICAL CHEMISTS. Official methods of analysis of AOAC International. $16^{\text {th }}$ ed. Gaitheersburg, 1997. cap. 39, p. 6-7.

[3] BLIGH, E. G.; DYER, W. J. A rapid method of total lipid extraction and purification. Canadian Journal of Biochemistry and Physiology, Otaawa, v. 37, n. 8, p. 911-917, aug. 1959.

[4] BOBBIO, F. O. et al. Identificação e quantificação das antocianinas do fruto do açaizeiro (Euterpe oleracea) Mart. Ciência e Tecnologia de Alimentos, Campinas, v. 20, n. 3, p. 388-390, set./dez. 2000.

[5] BOBBIO, F. O.; SCAMPARINI, A. R. P. Carbohydrates, organic acids and anthocyanin of Eugenia jambolana Lamark. Industrie Alimentari, Pinerolo, v. 21 , p. 296-298, apr. 1982.

[6] BRASIL. Ministério da Saúde. Secretaria de Vigilância Sanitária. Aprova Normas Técnicas Especiais do Estado de São Paulo, relativas a alimentos e bebidas. Resolução da Comissão Nacional de Normas e Padróes para Alimentos - CNNPA n. 12, de 24 de julho de 1978. Seção I, pt I. Disponível em: < http;//e-legis. bvs.br/leisref/public/showAct.php>. Acesso em: 13 mar. 2006.

[7] BRASIL. Ministério da Saúde. Secretaria de Vigilância Sanitária. Aprova revisão das Tabelas I, III, IV e V referente a aditivos intencionais, bem como os anexos I, II, III e VII, todos do Decreto $\mathrm{n}^{\circ} 55.871$, de 26 de março de 1965. Resolução CNS/MS n ${ }^{\circ} 04$, de 24 de Novembro de 1988. Diário Oficial da União, Brasília, DF, 19 dez. 1988, Seção 1, pt. 1. Disponível em: < http;//e-legis.bvs.
br/leisref/public/showAct.php>. Acesso em: 13 mar. 2006.

[8] BRAVO, L. Polyphenols: chemistry, dietary sources, metabolism, and nutritional significance. Nutrition Reviews, New York, v. 56, n. 11, p. 317-333, nov. 1988.

[9] CARVAlho, J. E. U.; MUlleR, C. H.; SilVA, R. F. Biometria e rendimento percentual de polpa de frutas da Amazônia, Comunicado Técnico, Belém, n. 139, out. 2005. Disponível em: <http://www.cpatu.embrapa. br/pat_2005/com_tec...>. Acesso em: 4 dez. 2005.

[10] CECCHI, H. M. Fundamentos teóricos e práticos em análise de alimentos. Campinas: Ed. da Unicamp. Coleção Livro Texto, 1999. p. 119.

[11] CONNOR, A. M. et al. Changes in fruit antioxidant activity among blueberry cultivars during cold-temperature storage. Journal of Agricultural and Food Chemistry, Easton, v. 50, n. 4, p. 893-898, feb. 2002.

[12] DULBOIS, M. et al., Colorimetria method for determination of sugars and related substances. Nature, Saint Paul, v. 28, n. 3, p. 350-356, mar. 1956.

[13] FULEKI, T.; FRANCIS, F. J. Quantitative methods for anthocyanins. 1. Extraction and determination of total anthocyanin in cranberries. Journal of Food Science, Chicago, v. 33, n. 1, p. 72-77, jan. 1968a.

[14] FULEKI, T.; FRANCIS, F. J. Quantitative methods for anthocyanins.2. Determination of total anthocyanin and degradation index for cranberry juice. Journal of Food Science, Chicago, v. 33, n. 1, p. 78-83, jan. 1968b.

[15] GLOBAL 21: Informes Setoriais: Fruticultura. Disponível em: <http://www.global21.com.br/informessetoriais/setor.asp?cod=6>. Acesso em: 31 out. 2005.

[16] GRANADA, G. G.; ZAMBIAZI, R. C.; MENDONÇA, C. R. B. Abacaxi: produção, mercado e subprodutos. Boletim do Centro de Pesquisa e Processamento de Alimentos, Curitiba, v. 22, n. 2, p. 405-422, jul./dez. 2004.

[17] GROSS, J. Pigments in fruits. London: Academic Press, 1987. 303 p.

[18] INTERNATIONAL ORGANIZATION FOR STANDARDIZATION. ISO 5497: Sensory Analisys-MethodologyGuidelines for the preparation os samples of which direct sensory analisys is not feasible. Genève, 1982. $4 \mathrm{p}$.

[19] JACKIX, M. H. Geléias e doces em massa. In: Doces, geléias e frutas em calda. 2. ed., São Paulo: Editora da Unicamp, 1988. cap. 7, p. 172.

[20] JOLY, A. B. Botânica: Introdução à taxonomia vegetal. 2. ed. São Paulo: Companhia Editora Nacional, 1979. p. 505.

[21] KISS, J. Estranhas no ninho. Globo Rural, ed. 210, abr. 2003. Disponível em: <http://www.revistagloborural. globo.com/EditoraGlobo/componentes/article/edg_article_print/...>. Acesso em: 7 set. 2006.

[22] LIMA, E. D. P. A. et al. Caracterização física e química dos frutos da umbu-cajazeira (Spondias spp) em cinco estádios de maturação, da polpa congelada e néctar. Revista Brasileira de Fruticultura, Jaboticabal, v. 24, n. 2, p. 388-343, ago. 2002. 
[23] LIMA, V. L. A. G.; MÉLO, E. A.; LIMA, D. E. S. Fenólicos e carotenóides totais em pitanga. Scientia Agrícola, Piracicaba, v. 59, n. 3, p. 447-450, jul./set. 2002.

[24] MILLER, G. L. Use of dinitrosalicylic acid reagent for determination of reducing sugar. Analytical Chemistry, Washington, v. 31, n. 3, p. 426-428, mar. 1958.

[25] MORTON, J. Jambolan. In: MORTON, J. Fruits of warm climates. Miami: Creative Resoursh Sistems, 1987. p. 375-378. Disponível em: <http://www.hort.purdue. edu/newcrop/morton/jambolan_ars.html > . Acesso em: 10 nov. 2005.

[26] MOTA, R. Caracterização do suco de amora-preta elaborado em extrator caseiro. Ciência e Tecnolologia de Alimentos, Campinas, v. 26, n. 2, p. 303-308, abr./jun. 2006.

[27] NACHTIGALL, A. M. et al. Geléias light de amora-preta. Boletim do Centro de Pesquisa e Processamento de Alimentos, Curitiba, n. 2, p. 337-354, jul./dez. 2004.

[28] PREGNOlATtO, W.; PREGNOLATTO, N. P. (Coord.) Normas analíticas do Instituto Adolfo Lutz: métodos químicos e físicos para análise de alimentos. 2. ed. São Paulo: INSTITUTO ADOLFO LUTZ, 1985. p. 25-27, 49-50, 232-233.

[29] ROCHA, F. G. et al., Características de geléias light de pêssego elaboradas com diferentes edulcorantes. In: SIMPOSIO EM CIÊNCIA DE ALIMENTOS - ALIMENTOS E SAÚDE, 2., 2003, Florianópolis. Anais ... Florianópolis: UFSC, 2003. p. 979 -1107.
[30] SHELUKHINA, N. P.; FEDICHIKINA, L. G. A rapid method for quantitative determination of pectic substances. Acta Botanica Neerlandica, Amsterdan, v. 43, n. 2, p. 205-207, june 1994.

[31] SILVA, F. O.; MARTINS, M. I. E.; ANDRIAZZI, C. V. G. Custo de implantação de lichia em dois espaçamentos, Estado de São Paulo. In: CONGRESSO BRASILEIRO DE FRUTICULTURA, XXVII, 2002, Belém, PA. Anais... Belém: UFPEL, 2002. Disponível em: <http://www. ufpel.tche.br/spfruti/anais_xvii_cbf/fitotecnia/300.htm $>$. Acesso em: 7 set. 2006.

[32] SOARES et al., Desidratação da polpa de acerola (Malpighia emarginata D. C.) pelo processo "foam-mat". Ciência e Tecnologia de Alimentos, Campinas, v. 2 , n. 2, p. 164-170, maio/ago. 2001.

[33] SOLER, M. P.; RADOMILLE, L. R.; TOCCHINI, R. Processamento. In: SOLER, M. P. Industrialização de Frutas - Manual Técnico. Campinas: Instituto de Tecnologia de Alimentos - ITAL, 1986, cap. IV, p. 127-140.

[34] Tabela brasileira de composição de alimentos - TACO. Versão II. 2. ed. Campinas: NEPA - UNICAMP, 2006. Disponível em: <http://www.unicamp.br/nepa/taco/contar/tabela1_pdf.pdf $>$. Acesso em: 18 nov. 2005.

[35] WANG, S. Y.; LIN, H. -S. Antioxidant activity in fruits and leaves of blackberry, raspberry, and strawberry varies with cultivar and developmental stage. Journal of Agricultural and Food Chemistry, v. 48, n. 2 , p. 140-146, feb. 2000. 